\title{
Insomnia and sleep apnea in midlife women: prevalence and consequences to health and functioning
}

\author{
Martica H. Hall ${ }^{* 1}$, Christopher E. Kline ${ }^{1}$, and Sara Nowakowski ${ }^{2}$
}

\author{
Addresses: ${ }^{1}$ Department of Psychiatry, University of Pittsburgh School of Medicine, 3811 O'Hara Street, Pittsburgh, PA 15213, USA; \\ ${ }^{2}$ Department of Obstetrics and Gynecology, University of Texas Medical Branch, 301 University Boulevard, Galveston, TX 77555-0587, USA \\ *Corresponding author: Martica H. Hall (hallmh@upmc.edu) \\ Fl000Prime Reports 2015, 7:63 (doi:10.12703/P7-63) \\ All FI000Prime Reports articles are distributed under the terms of the Creative Commons Attribution-Non Commercial License \\ (http://creativecommons.org/licenses/by-nc/3.0/legalcode), which permits non-commercial use, distribution, and reproduction in any medium, \\ provided the original work is properly cited. \\ The electronic version of this article is the complete one and can be found at: http://f1000.com/prime/reports/m/63
}

\begin{abstract}
Sleep disturbance is common during the menopausal transition, with numerous downstream consequences to health and functioning, including reduced quality of life, impaired mental health, and increased physical health morbidity. Insomnia affects approximately 50\% of midlife women and is characterized by nocturnal symptoms of difficulties initiating or maintaining sleep (or both) and daytime symptoms that impair occupational, social, or other components of functioning. In addition, approximately $20 \%$ of midlife women develop sleep-disordered breathing during the menopausal transition. This commentary summarizes the prevalence, risk factors, and treatment options for each of these sleep disorders in midlife women, with specific focus on first-line treatments for insomnia (cognitive behavioral therapy for insomnia) and sleep-disordered breathing (continuous positive airway pressure) and unique considerations for treating sleep disorders in midlife women. Future directions are also discussed.
\end{abstract}

\section{Introduction}

Midlife women are at increased risk for insomnia and sleep-disordered breathing (SDB). In fact, disturbed sleep is such a hallmark of the menopausal transition that it was recognized as a core symptom of menopause in the 2005 National Institutes of Health (NIH) State-of-the-Science Conference panel report on menopause-related symptoms [1]. Menopause is defined as the cessation of menstruation because of degeneration of ovaries and follicles accompanied by changing levels of ovarian hormone (estrogen and progesterone). The World Health Organization [2] further defines menopause as the permanent cessation of menstrual periods that occurs naturally or is induced by surgery, chemotherapy, or radiation. Menopause may also be characterized by the transition from pre- to peri- to postmenopausal status, as defined by standardized criteria [3].

Menopause-related sleep disturbances are a significant public health problem because of their potential negative impact on quality of life, mental health, workplace productivity, health-care utilization, and disease morbidity
[4-7]. This commentary provides a brief summary of the prevalence, risk factors, and treatment options for insomnia and sleep- disordered breathing, the two most common sleep disorders in midlife women. We close with a call for additional research to advance our understanding of the pathophysiology of sleep disturbances in midlife women and for the development and testing of interventions to ameliorate these common and consequential sleep disorders. Each disorder is uniquely described, given differences in present knowledge and empirical support for insomnia and SDB with respect to the menopausal transition. Our discussion of insomnia focuses on treatment, which can be multifactorial and complex, and our discussion of SDB includes more detail regarding risk factors and consequences in midlife women.

\section{Insomnia disorder \\ Prevalence, risk factors, and consequences}

The prevalence of insomnia, defined as nocturnal symptoms of difficulties initiating or maintaining sleep (or both) 3 times per week for a period of at least 3 months 
and daytime symptoms that impair occupational, social, or other areas of functioning, is estimated at $39-60 \%$ in peri- and post-menopausal women $[1,8,9]$. The health and functional consequences of insomnia in midlife women include reduced quality of life, increased healthcare utilization and costs [4], disability [4], and risk for psychiatric and medical conditions (for example, depression and cardiovascular disease, or CVD) $[10,11]$. It remains unclear whether insomnia that occurs during the menopausal transition differs from insomnia during other stages of life. However, there are many factors that may complicate the development and maintenance of insomnia during menopause, including the effects of aging on sleep (for example, diminished sleep need and changes in sleep continuity and architecture) [12-14] as well as changes in the hormonal milieu, hot flashes, depression, anxiety, or comorbid medical conditions (for example, chronic pain) or a combination of these. For example, hot flashes occur in $60-80 \%$ of women during the menopausal transition [15] and persist for $4-5$ years on average $[16,17]$. When hot flashes occur during the night, they frequently but not invariably awaken women from sleep $[18,19]$. Indeed, insomnia can occur during menopause independently of nocturnal hot flashes [20]. Although the precipitants of insomnia during menopause remain unclear, behavioral conditioning and certain behaviors (that is, sleep habits) may prolong insomnia, as described by Spielman's three-factor model of insomnia [21]. Among midlife women, distress about nocturnal hot flashes and their impact on sleep can lead to sleep habits that perpetuate insomnia, including spending too much time in bed, 'sleeping in' in the morning, and napping during the day [22].

\section{Treatment}

Psychotherapeutic and pharmacologic approaches may be used to treat insomnia in midlife women, as described below. The most widely used non-pharmacologic approach is cognitive behavioral therapy for insomnia (CBTI), which is a structured, skill-focused psychotherapy that includes components of cognitive therapy (challenging unhelpful beliefs about sleep), behavioral techniques (sleep restriction, stimulus control therapy, and relaxation techniques), and education about sleep. Therapeutic techniques that may benefit other menopausal symptoms (for example, hot flashes and depression) may also be used to augment CBTI in midlife women [23-26]. Below, we review individual components of CBTI, including specific strategies that may be appropriate to insomnia in midlife women.

\section{Sleep restriction}

Sleep restriction is used to consolidate sleep in patients with insomnia. Although it may seem paradoxical to reduce the time a patient with insomnia stays in bed, sleep restriction addresses a mismatch between the amount of time spent in bed and the amount of time spent asleep; effectively, restricting insomnia patients' time in bed improves their sleep efficiency (time spent asleep/time in bed $\times 100$ ) [27]. At a physiological level, sleep restriction improves sleep efficiency by increasing the patient's homeostatic drive for sleep.

Sleep restriction therapy in CBTI is accomplished over a number of weeks. The clinician first must assess the patient's current sleep habits, including the timing of sleep (clock time at which the patient gets into and out of bed), the total amount of time spent in bed (hours between getting into and out of bed), and sleep duration (time spent asleep). These data are usually collected by using daily sleep diaries over a 1 - to 2-week period. In the second step of sleep restriction therapy, the clinician prescribes the timing and duration of time in bed on the basis of the patient's average sleep duration. For example, sleep restriction in an insomnia patient with an average time in bed of 8.5 hours and average sleep duration of 7 hours would entail a new time in bed of 7 hours. Sleep restriction generally entails changing a patient's bed time, as rise time is often dictated by circumstances such as work schedule and family responsibilities. Patients continue to complete daily sleep diaries during sleep restriction so that they and their clinician can monitor sleep efficiency and adjust sleep duration accordingly. As the patient's sleep efficiency increases, time in bed is lengthened in 15- to 30-minute increments over subsequent weeks until an optimal quantity of sleep is achieved without decreasing average sleep efficiency to below $85 \%$. More detailed information on the delivery of sleep restriction therapy is available in published guidelines (for example, Treatment Plans and Interventions for Insomnia by Manber and Carney [28], Overcoming Insomnia: A Cognitive-Behavioral Therapy Approach Workbook by Edinger and Carney [29], and Cognitive Behavioral Treatment of Insomnia: A Session-bySession Guide by Perlis and colleagues [30]).

Increased daytime sleepiness is a common side effect at the start of sleep restriction therapy. It is, thus, important that patients be made aware of and monitored for the risk of increased daytime sleepiness. Prescribed increases in time in bed over the course of sleep restriction therapy attenuate daytime sleepiness. Sleep restriction therapy is inadvisable for individuals whose jobs require heightened vigilance to avoid accidents (for example, professional drivers, pilots, air traffic controllers, and machine operators). Other contraindications include conditions that can be exacerbated by sleepiness or deep sleep (for example, epilepsy, parasomnias, and SDB). Risk for 
sleep apnea should be evaluated (for example, reports of loud snoring, pauses in breathing, gasping for breath, daytime sleepiness, and obesity), and referrals for formal assessment and treatment should be made prior to initiating sleep restriction therapy; this caution is especially important in midlife women given the increased prevalence in sleep apnea during the menopausal transition (see the following section).

\section{Stimulus control}

In insomnia, the bed and bedroom can become associated with frustration, intrusive thoughts, anxiety and distress, and elevated physiological arousal, which, in turn, perpetuate the patient's inability to sleep [31]. Using principles of classic conditioning theory [32,33], Bootzin $[32,34]$ designed stimulus control therapy for insomnia, which strengthens conditioned associations between the bed and bedroom as cues for sleep and extinguishes the conditioned arousal response to the bed and bedroom. Stimulus control therapy prescribes that the patient go to bed when sleepy, get out of bed when they are unable to sleep, and engage in quiet activities away from the bed and bedroom until they are sleepy, at which time they return to bed. The bed is limited to sleep and sexual activity. Participants are also instructed to maintain a consistent wake time and avoid napping during the day. Modifications to the stimulus control instructions may be necessary in midlife women for whom leaving the bed during the night is contraindicated, as in individuals at risk for falls, or in women who are disabled and cannot leave the bed without assistance.

\section{Cognitive therapy}

Principles of cognitive therapy for insomnia are designed to challenge maladaptive beliefs and attitudes that serve to maintain insomnia. Worrying, faulty attributions, or unrealistic expectations of sleep may lead to increased emotional distress, feeding a vicious cycle that maintains and may exacerbate disturbed sleep in midlife women (for example, "If I don't get my 8 hours of sleep, I'm useless."). Challenging unhelpful beliefs about sleep will decrease an individual's anxiety and arousal $[35,36]$. The first step is to make the patient aware of her unhelpful sleep beliefs. Once these beliefs are identified, the individual is taught to challenge their unhelpful beliefs through guided discovery. The patient is encouraged to view her thoughts as one of the many possible interpretations instead of the absolute truth (for example, "I don't even know whether I'll get a good sleep tonight."). The final step is to replace dysfunctional cognitions with alternative interpretations that are more adaptive and realistic and that are based on past evidence (for example, "Despite feeling bad at work, I do a good job
99.9\% of the time."). Menopausal women experiencing hot flashes may also have maladaptive thoughts related to hot flashes (for example, "It seems as if I'll never feel like myself again."). Cognitive therapy techniques can also teach women to apply effective cognitive reframing skills to unhelpful thoughts about hot flashes. Women who cope with hot flashes by using disclosure to others or self-talk ("Letting the flash pass without being hooked by the feelings.") and by staying calm ("I can just relax and accept it.") report less distress about hot flashes [37-39].

\section{Relaxation training}

Relaxation techniques can be effective in reducing physiological hyperarousal and are especially effective in helping with sleep initiation [40-42]. Relaxation techniques commonly used to treat insomnia include progressive muscle relaxation, body scanning (a form of mindfulness meditation focusing attention on particular body parts (for example, Jon Kabat-Zinn's Mindfulness for Beginners [43]), autogenic training (that is, visualizing a calming scene), and diaphragmatic breathing. Because there is little evidence to suggest differential effectiveness for insomnia across these relaxation techniques [44], patients may select the technique that feels most appropriate to them. These techniques may be practiced in bed before going to sleep or during awakenings from sleep. Relaxation techniques may be especially helpful to midlife women who experience hot flashes $[45,46]$. Although the exact mechanism of hot flashes is not clear, they appear to be mediated by increased sympathetic nervous system activity [47]. This knowledge has generated considerable interest in the idea that reducing stress may reduce hot flashes by reducing central sympathetic activation. In this context, paced respiration may be an effective tool to reduce stress, hot flashes, and their impact on symptoms of insomnia $[48,49]$.

\section{Sleep hygiene}

Sleep hygiene therapy seeks to identify and correct behaviors and environmental factors that may interfere with or enhance sleep in insomnia. Sleep hygiene therapy is most effective when used in conjunction with other components of CBTI $[41,50]$. Examples of sleep-interfering factors are use of caffeine throughout the day, use of alcohol to induce sleep, and a bedroom environment that is bright, hot, and noisy. Sleep hygiene recommendations in midlife women with insomnia might include wearing lighter pajamas to bed and keeping a second pair near the bed, using lighter bedding and layering, keeping the ambient room temperature cool, keeping a fan nearby and a cool beverage near the bed, limiting caffeine products throughout the day, and avoiding alcohol and smoking. 


\section{Pharmacologic therapy}

Sedative hypnotics, including zaleplon (Sonata; King Pharmaceuticals, Bristol, TN, USA), zolpidem (Ambien; Sanofi, Paris, France) [51], and eszopiclone (Lunesta; Sunovion Pharmaceuticals Inc., Marlborough, MA, USA), are effective for the treatment of acute insomnia [52]. However, tolerance, withdrawal, dependence, and rebound insomnia at discontinuation may occur when sedative hypnotics are used for more than 2 weeks [53]. Sex differences in their pharmacokinetics and side effect profiles, including increased risk of cognitive impairment in the morning and motor vehicle accidents, led the US Food and Drug Administration to require the manufacturers of Ambien and Lunesta to lower recommended starting doses in women. The recommended starting dose of zolpidem for women was lowered from 10 to $5 \mathrm{mg}$ for immediate-release products and from 12.5 to $6.25 \mathrm{mg}$ for extended-release products. The recommended starting dose of eszopiclone for women was lowered from 2 to $1 \mathrm{mg}$. Although dosing differences have been identified for zolpidem and eszopiclone, other sedative hypnotics may also differ with respect to their pharmacokinetics, including rates of absorption, metabolism, and excretion. Ramelteon, a selective melatonin receptor agonist, shows promise for the treatment of insomnia without the side effect profile associated with sedative hypnotics [54].

\section{Summary and future directions}

The weight of evidence supporting CBTI, summarized in several meta-analyses $[42,55,56]$, led to its recognition as a first-line treatment for insomnia by the NIH Consensus Statement [1] and the British Association of Psychopharmacology [57]. Improvements following CBTI are equivalent to those achieved during acute treatment with hypnotic medications [58,59], and its effects are more durable after treatment discontinuation [58]. CBTI has also been shown to be efficacious for the treatment of chronic insomnia in older adults, including mid- and late-life women $[58,60]$. CBTI can be readily adapted to the sleep disturbances often reported during the menopausal transition $[8,19]$. However, to date, no randomized clinical trials have been conducted to examine the efficacy of CBTI in menopausal women or identify special considerations for tailoring CBTI to midlife. We are aware of only one study that has evaluated CBTI in women who reported that " $m y$ sleep is affected by menopause" [61]. Preliminary data from this open trial revealed a significant reduction in symptoms of insomnia and depression from pre- to post-CBTI [61]. Although these data are promising, randomized clinical trials are needed to quantify the efficacy of CBTI or modified CBTI (or both) for insomnia during the menopausal transition. Based on its efficacy and durability in other populations, CBTI holds promise for treating the increased incidence of insomnia in midlife women during the menopausal transition and beyond. Studies that evaluate the extent to which CBTI ameliorates medical risk associated with menopause, such as CVD and diabetes [62-64], are also needed.

The most significant barrier to dissemination of CBTI in midlife women with insomnia is the number of health-care providers trained to deliver this efficacious and durable treatment. There are too few behavioral sleep medicine specialists certified by the American Board of Sleep Medicine to diagnose and treat insomnia in the community. A recent national Veterans Affairs training initiative $[65,66]$ has been instituted to train a broader range of health-care providers in the delivery of CBTI, including primary care clinicians, nurse practitioners, and licensed social workers. Health-care providers without expertise in the diagnosis and management of insomnia may also seek referrals for board-certified behavioral sleep medicine specialists through the Society for Behavioral Sleep Medicine website (www.behavioralsleep.org/ findspecialist.aspx). Also available to health-care providers and the public are a variety of commercially available self-help books (for example, Carney and Manber's Quiet Your Mind and Get to Sleep [67]), internet-based CBTI programs (for example, www.sleepio.com and www.shuti. me), and mobile applications (for example, CBT-i Coach).

\section{Obstructive sleep apnea}

SDB is an umbrella term that encompasses a variety of sleep disorders defined by abnormal respiration during sleep. As the most common form of SDB, obstructive sleep apnea (OSA) is characterized by recurrent episodes of significant airflow reduction (hypopnea) or cessation (apnea) due to upper airway narrowing or collapse, respectively, despite continued respiratory effort. A brief arousal is often required to reestablish airway patency. This repeated pattern of breathing pauses and arousals results in recurring bouts of intermittent blood oxyhemoglobin desaturation and increased sympathetic activity, respectively, throughout the night. SDB severity is derived from overnight polysomnography and calculated as the number of apneas and hypopneas per hour of sleep (apnea-hypopnea index, or AHI). AHI values of 5 to less than 15,15 to less than 30 , and at least 30 represent mild, moderate, and severe disease categories, respectively [68].

Across multiple races and ethnicities and without regard to age and obesity status, recent estimates indicate that approximately $20 \%$ of women have at least mild OSA (AHI of at least 5 ) and that $6 \%$ have moderate to severe 
OSA (AHI of at least 15) [69,70]. This represents a significant increase in OSA prevalence over the last 20 years and is largely attributed to an aging society and increased obesity [69]. Nevertheless, these statistics mask the dramatic increase in OSA risk for midlife women: in one study, the prevalence of moderate to severe OSA progressed from less than 3\% in women who are 30-49 years old to $9 \%$ for women who are at least 50 years old [69]; in another study, OSA prevalence estimates were 4, 17 , and $43 \%$ among women who are 20-44, 45-54, and 55-70 years old, respectively [71]. Indeed, a recent study from a community-based sample of midlife women reported that $20 \%$ of the sample had moderate to severe OSA [72].

\section{Signs and symptoms of obstructive sleep apnea and diagnosis}

Standard signs and symptoms of OSA include snoring, witnessed apneas, and daytime sleepiness. However, women with OSA often have a different clinical presentation, commonly reporting insomnia-like complaints such as fatigue or poor sleep quality along with mood disturbance $[73,74]$. These atypical OSA symptoms may divert clinicians from suspecting OSA; however, clinical studies have found that the majority of postmenopausal women who present with insomnia symptoms actually have significant OSA.

The standard method of OSA diagnosis is laboratory polysomnography that includes assessment of breathing, respiratory effort, and oxyhemoglobin saturation, although home-based testing using limited-channel devices is gaining popularity and acceptance in sleep medicine [75]. The vast majority of women with OSA have not been clinically diagnosed $[76,77]$, and this is likely owing to the different manifestation of OSA symptoms and lower likelihood of being prompted by their partner to seek treatment [78].

\section{Risk factors for obstructive sleep apnea}

Midlife seems to be a time of increased OSA prevalence for women because of three interrelated factors: the menopausal transition, weight gain, and aging [79]. Although OSA is relatively rare among premenopausal women, its prevalence dramatically increases with menopause [80-82]. Postmenopausal women are 3.5 times more likely than premenopausal women to have moderate or severe OSA, even after adjustment for age and body mass index (BMI) [80]. It is commonly believed that estrogen and progesterone confer protection from OSA, likely by enhancing upper airway dilator function and respiratory control during sleep [83-85], but this has yet to be comprehensively examined in large well-controlled studies. Moreover, some observational $[79,80,86]$ and treatment [87-89] studies have found that hormone replacement therapy (HRT) is associated with reduced OSA risk and severity among postmenopausal women, whereas others have failed to demonstrate any effect of HRT on OSA risk [90-92]. Thus, the diminished production of these reproductive hormones with menopause may increase OSA risk among midlife women, although the available evidence is not entirely consistent.

Obesity is the strongest risk factor for OSA among adults [93] and undoubtedly plays a key role in the development and progression of OSA among midlife women, as the menopausal transition is associated with significant weight gain and greater central fat deposition [94]. However, the association between weight and OSA may be less important compared with males, as females have a higher BMI at each category of OSA severity [95] and the longitudinal association between changes in BMI and AHI is weaker among women compared with men $[96,97]$. This difference may be due to the distribution of excess weight, since the central fat distribution often seen in males is more likely to impact OSA risk compared with the peripheral fat distribution commonly observed in females [98].

Finally, age and poor sleep quality are important risk factors for OSA in midlife women. The risk of OSA increases steadily with age across adulthood until reaching a plateau at approximately 70 years $[70,99]$. In addition to weight gain that accompanies aging [94], upper airway collapsibility increases with age $[100,101]$. Poor sleep also predisposes to OSA: fragmented sleep increases OSA frequency, whereas slow-wave sleep is protective against OSA $[102,103]$. Midlife women experience decreased subjective, though not necessarily objective, sleep quality [19], and the age-related decline in sleep efficiency is greater among women compared with men [13].

\section{Health consequences}

Untreated OSA of at least moderate severity is independently associated with numerous health consequences, including cognitive impairment [104], mood disturbance [105], metabolic dysfunction [106], CVD [107], and early mortality [108]. Most studies on the health consequences of OSA have consisted primarily of male samples or have not examined whether the health risk of OSA differs by sex. The few studies that have examined sex differences in the health consequences of OSA have focused on CVD risk but have had equivocal findings [109-112]. Similarly, only a handful of studies have 
exclusively focused on the health consequences of OSA in women. Each of these studies has focused on metabolic or CVD risk, and OSA was significantly associated with higher CVD surrogates [113] and greater risk for the metabolic syndrome [114], coronary heart disease and stroke [115], and CVD mortality [116]. As a prominent example, Theorell-Haglöw and colleagues [114] found that $57 \%$ of women with severe OSA had the metabolic syndrome compared with only $11 \%$ of women without OSA. Likewise, studies that focused exclusively on midlife women have found OSA to be associated with greater metabolic syndrome prevalence and higher levels of inflammatory and coagulation biomarkers that are prognostic for CVD and type 2 diabetes (for example, C-reactive protein, fibrinogen, and plasminogen activator inhibitor-1) $[117,118]$. It is important to note, however, that this literature is dependent on observational studies and cannot directly address causality; future studies that are specifically designed and powered to address causation are needed.

\section{Treatment}

Continuous positive airway pressure (CPAP) is the conventional treatment for OSA. With this therapy, a machine delivers a constant flow of air to the patient's airway via a nasal, facial, or oral interface, effectively providing a pneumatic splint to maintain airway patency during sleep. Although CPAP is highly efficacious when used, numerous studies have demonstrated that adherence is a notable problem as, on average, less than one half of adults prescribed CPAP use the device at least 4 hours per night [119]. However, research examining whether CPAP adherence differs by sex has provided inconsistent findings, with studies indicating greater [120], lower [121,122], or similar [123-125] CPAP compliance in women compared with men. Similarly, whether treatment response differs between men and women is unclear-the only study to examine this found similar improvements between middle-aged men and women in daytime functioning following CPAP therapy [125]. Two observational studies, using the same cohort of women with suspected OSA, found CPAP treatment to be associated with a reversal of the CVD morbidity and mortality risk observed for severe OSA $[115,116]$. Unfortunately, no studies have focused on the predictors of CPAP adherence or treatment outcomes associated with CPAP use in midlife women.

Oral appliances and weight loss represent the most common treatment alternatives to CPAP. As devices that reposition the lower jaw and soft tissue structures of the mouth to increase upper airway size during sleep, oral appliances are a primary treatment option for adults with mild to moderate OSA and for those who cannot tolerate CPAP. Studies have generally found that oral appliances have a rate of treatment success (defined as an AHI of less than 10) of approximately 50\% [126]. The only study to examine sex differences in oral appliance treatment response found that women were more than twice as likely to experience treatment success compared with men [127]. Alternatively, because excess weight is such a strong determinant of OSA risk [93], lifestyle interventions that focus on weight loss are commonly recommended in the management of OSA [128]. However, weight loss is associated with a smaller AHI reduction in females compared with males [97], and one randomized trial found that a lifestyle intervention was less effective at reducing $\mathrm{AHI}$ in women compared with men at 1 year [129] but not at 4 years [130]. Again, similar to CPAP research, no studies have specifically examined the efficacy, predictors, or outcomes associated with oral appliance or weight loss therapies for midlife women.

Finally, some experimental trials have found HRT to reduce OSA severity in postmenopausal women [87-89], although multiple studies have failed to observe such an effect [90-92]. Given the inconsistent findings of HRT on treatment efficacy and its known health risks (for example, breast cancer and venous thromboembolic disease), HRT is not recommended for treating OSA in postmenopausal women [131]. Thus, treatment considerations for midlife women with OSA do not appreciably differ from those recommended for the general adult population with OSA [132-134].

\section{Important future directions}

Much of the research involving the health consequences of OSA, adherence to OSA treatment options, and responses to OSA treatment has focused on males [135]. However, because women differ from men in the underlying pathophysiology and clinical presentation of OSA, these issues need to be explored in women. A focus on midlife women-who experience the greatest increase in OSA prevalence and, as a result, may benefit the most from early identification and intervention-seems especially warranted. In particular, efforts to attenuate the development, progression, and health consequences of OSA among midlife women should be explored.

\section{Conclusions}

Insomnia and SDB are common in midlife women and this is due, in part, to both direct and indirect consequences of menopause and aging. Although research has not specifically linked menopause-related sleep disturbances to morbidity and mortality, mounting evidence suggests that insomnia and SDB are significant risk factors for cardiometabolic disease and mortality $[64,108,136]$. 
Fortunately, there are effective treatment options for both disorders, although interventions may benefit from being tailored to midlife women, including the impact of nocturnal vasomotor symptoms on insomnia and apnea and motivational interviewing strategies to enhance compliance and effectiveness. Treatment of sleep disturbances in midlife women may have direct effects on quality of life as well as more downstream effects on mental and physical health, including both health span and life span.

\section{Abbreviations}

AHI, apnea-hypopnea index; BMI, body mass index; CBTI, cognitive behavioral therapy for insomnia; CPAP, continuous positive airway pressure; $\mathrm{CVD}$, cardiovascular disease; HRT, hormone replacement therapy; NIH, National Institutes of Health; OSA, obstructive sleep apnea; SDB, sleep-disordered breathing.

\section{Disclosures}

The authors declare that they have no disclosures.

\section{Acknowledgments}

Funding for the authors was provided, in part, by grants from the National Institutes of Health to Martica H. Hall (\#HL104607), Christopher E. Kline (\#HL118318), and Sara Nowakowski (\#NR014008).

\section{References}

I. NIH: National Institutes of Health State-of-the-Science Conference statement: management of menopause-related symptoms. Ann Intern Med 2005, I 42(I2): 1003-13.

2. World Health Organization Scientific Group. Research on the Menopause in the 1990s. Geneva: World Health Organization, 1996.

3. Soules MR, Sherman S, Parrott E, Rebar R, Santoro N, Utian W, Woods N: Executive summary: Stages of Reproductive Aging Workshop (STRAW). Climacteric 200I, 4(4):267-72.

4. Bolge SC, Balkrishnan R, Kannan H, Seal B, Drake CL: Burden associated with chronic sleep maintenance insomnia characterized by nighttime awakenings among women with menopausal symptoms. Menopause 2010, I7(1):80-6.

5. Sarsour K, Kalsekar A, Swindle R, Foley K, Walsh JK: The association between insomnia severity and healthcare and productivity costs in a health plan sample. Sleep 201 I Apr, 34(4):443-50.

6. Jennum P, Kjellberg J: Health, social and economical consequences of sleep-disordered breathing: a controlled national study. Thorax 201 I Jul, 66(7):560-6.

7. Cappuccio FP, D'Elia L, Strazzullo P, Miller MA: Sleep duration and all-cause mortality: a systematic review and meta-analysis of prospective studies. Sleep 2010 May, 33(5):585-92.

8. Kravitz HM, Ganz PA, Bromberger J, Powell LH, Sutton-Tyrrell K, Meyer PM: Sleep difficulty in women at midlife: a community survey of sleep and the menopausal transition. Menopause 2003, 10(1):19-28.

\section{FlOOOPrime}

9. Kravitz HM, Zhao X, Bromberger JT, Gold EB, Hall MH, Matthews KA, Sowers MR: Sleep disturbance during the menopausal transition in a multi-ethnic community sample of women. Sleep 2008, 3 I (7):979-90.
10. Buysse DJ: Diagnosis and assessment of sleep and circadian rhythm disorders. J Psychiatr Pract 2005, I I (2): I02- 15.

II. Vgontzas AN, Liao D, Bixler EO, Chrousos GP, Vela-Bueno A: Insomnia with objective short sleep duration is associated with a high risk for hypertension. Sleep 2009, 32(4):49I-7.

\section{FlOOOPrime}

\section{RECOMMENDED}

12. Hirshkowitz M, Whiton K, Albert SM, Alessi C, Bruni O, DonCarlos L, Hazen N, Herman J, Katz ES, Kheirandish-Gozal L, Neubauer DN, O'Donnell AE, Ohayon MM, Peever J, Rawding R, Sachdeva RC, Setters B, Vitiello MV, Ware JC: National Sleep Foundations' sleep time duration recommendations: methodology and results summary. Sleep Health 20I5, I(I):40-3.

13. Ohayon MM, Carskadon MA, Guilleminault C, Vitiello MV: Metaanalysis of quantitative sleep parameters from childhood to old age in healthy individuals: developing normative sleep values across the human lifespan. Sleep 2004 Nov I, 27(7): 1255-73.

14. Carrier J, Land S, Buysse DJ, Kupfer DJ, Monk TH: The effects of age and gender on sleep EEG power spectral density in the middle years of life (aged 20-60 years old). Psychophysiology 200 I, 38:232-42.

15. Gold EB, Sternfeld B, Kelsey JL, Brown C, Mouton C, Reame N, Salamone L, Stellato R: Relation of demographic and lifestyle factors to symptoms in a multi-racial/ethnic population of women 40-55 years of age. Am J Epidemiol 2000, I52(5):463-73.

16. Col NF, Guthrie JR, Politi M, Dennerstein L: Duration of vasomotor symptoms in middle-aged women: a longitudinal study. Menopause 2009, 16(3):453-7.

17. Politi MC, Schleinitz MD, Col NF: Revisiting the duration of vasomotor symptoms of menopause: a meta-analysis. J Gen Intern Med 2008, 23(9):1507-13.

18. Shaver J, Giblin E, Lentz M, Lee K: Sleep patterns and stability in perimenopausal women. Sleep $1988 \mathrm{Dec}$ I I (6):556-6 I.

19. Young T, Rabago D, Zgierska A, Austin D, Laurel F: Objective and subjective sleep quality in premenopausal, perimenopausal, and postmenopausal women in the Wisconsin Sleep Cohort Study. Sleep 2003 Sep, 26(6):667-72.

20. Okun ML, Kravitz HM, Sowers MF, Moul DE, Buysse DJ, Hall M: Psychometric evaluation of the Insomnia Symptom Questionnaire: a self-report measure to identify chronic insomnia. J Clin Sleep Med 2009 Feb I5, 5(I):4I-5I.

21. Spielman AJ, Caruso LS, Glovinsky PB: A behavioral perspective on insomnia treatment. Psychiatr Clin North Am 1987 Dec, I 0(4):54I-53.

22. Krystal AD, Edinger J, Wohlgemuth W, Marsh GR: Sleep in perimenopausal and post-menopausal women. Sleep Med Rev 1998, 2(4):243-53.

23. Alder J, Eymann BK, Armbruster U, Decio R, Gairing A, Kang A, Bitzer J: Cognitive-behavioural group intervention for climacteric syndrome. Psychother Psychosom 2006, 75(5):298-303.

24. Allen LA, Dobkin RD, Boohar EM, Woolfolk RL: Cognitive behavior therapy for menopausal hot flashes: two case reports. Maturitas 2006 Apr 20, 54(I):95-9.

25. Carpenter JS, Neal JG, Payne J, Kimmick G, Storniolo AM: Cognitivebehavioral intervention for hot flashes. Oncol Nurs Forum 2007 Jan, 34(I):37.

26. Keefer L, Blanchard EB: A behavioral group treatment program for menopausal hot flashes: results of a pilot study. Appl Psychophysiol Biofeedback 2005 Mar, 30(I):2I-30.

27. Spielman AJ, Saskin P, Thorpy MJ: Treatment of chronic insomnia by restriction of time in bed. Sleep 1987, 10(I):45-56.

FIOOOPrime
RECOMMENDED

28. Manber R, Carney CE: Treatment Plans and Interventions for Insomnia: A Case Formulation Approach. New York: The Guilford Press, 2015.

29. Edinger JD, Carney CE: Overcoming Insomnia: A Cognitive-Behavioral Therapy Approach Workbook (Treatments That Work). Ist edition ed. Oxford University Press, Inc., 2008. 
30. Perlis ML, Smith MT, Jungquist C, Posner D: Cognitive behavioral treatment of insomnia: A session-by-session guide. First ed. New York: Springer Verlag, 2005.

31. Perlis ML, Giles DE, Mendelson WB, Bootzin RR, Wyatt JK: Psychophysiological insomnia: the behavioural model and a neurocognitive perspective. J Sleep Res 1997 Sep, 6(3): 179-88.

32. Bootzin R: Effects of self-control procedures for insomnia. In: Stuart RB, ed. Behavioral Self-Management Strategies and Outcomes. New York: Brunner/Mazel, 1977.

33. Bootzin RR, Nicassio PM: Behavioral treatments of insomnia. In: Hersen M, Eisler RE, Miller PM, eds. Progress in behavior modification (Vol. 6). New York: Academic Press, 1978: I-45.

34. Bootzin RR: Stimulus control treatment for insomnia. Proceedings of the American Psychological Association 1972, 7:395-6.

35. Harvey AG, Greenall E: Catastrophic worry in primary insomnia. J Behav Ther Exp Psychiatry 2003 Mar, 34(I):II-23.

\section{FIOOOPRime}

36. Harvey AG, Tang NK, Browning L: Cognitive approaches to insomnia. Clin Psychol Rev 2005 Jul, 25(5):593-6II.

37. Hunter MS, Liao KL: A psychological analysis of menopausal hot flushes. Br J Clin Psychol 1995 Nov, 34(Pt 4):589-99.

38. Hunter MS, Mann E: A cognitive model of menopausal hot flushes and night sweats. J Psychosom Res 2010 Nov, 69(5):49I-50I.

39. Reynolds FA: Perceived control over menopausal hot flushes: exploring the correlates of a standardised measure. Maturitas 1997 Jul, 27(3):2I5-2I.

40. Means MK, Lichstein KL, Epperson MT, Johnson CT: Relaxation therapy for insomnia: nighttime and day time effects. Behav Res Ther 2000 Jul, 38(7):665-78.

4I. Morgenthaler T, Kramer M, Alessi C, Friedman L, Boehlecke B, Brown T, Coleman J, Kapur V, Lee-Chiong T, Owens J, Pancer J, Swick T: Practice parameters for the psychological and behavioral treatment of insomnia: an update. An american academy of sleep medicine report. Sleep 2006 Nov, 29( I I): 1415-9.

FlOOOPrime RECOMMENDED

42. Morin CM, Culbert JP, Schwartz SM: Nonpharmacological interventions for insomnia: a meta-analysis of treatment efficacy. Am J Psychiatry 1994, I5 I (8): I I72-80.

43. Kabat-Zinn J. Mindfulness for Beginners. Boulder, CO: Sounds Tru, Inc., 2012.

44. Coursey RD, Frankel BL, Gaarder KR, Mott DE: A comparison of relaxation techniques with electrosleep therapy for chronic, sleep-onset insomnia a sleep-EEG study. Biofeedback Self Regul 1980 Mar, 5(I):57-73.

45. Lindh-Astrand L, Nedstrand E: Effects of applied relaxation on vasomotor symptoms in postmenopausal women: a randomized controlled trial. Menopause $2013 \mathrm{Apr}$, 20(4):40I-8.

\section{FlOOOPrime RECOMMENDED}

46. Saensak S, Vutyavanich T, Somboonporn W, Srisurapanont M: Effectiveness of a modified version of the applied relaxation technique in treatment of perimenopausal and postmenopausal symptoms. Int J Womens Health 2013, 5:765-71.

\section{FlOOOPrime}

47. Kronenberg F: Hot flashes: Emidemiology and physiology. Ann NY Acad Sc 1990, 592:52-86.

48. Carpenter JS, Burns DS, Wu J, Otte JL, Schneider B, Ryker K, Tallman E, Yu M: Paced respiration for vasomotor and other menopausal symptoms: a randomized, controlled trial. J Gen Intern Med 20I3 Feb, 28(2): 193-200.

49. Sood R, Sood A, Wolf SL, Linquist BM, Liu H, Sloan JA, Satele DV, Loprinzi CL, Barton DL: Paced breathing compared with usual breathing for hot flashes. Menopause $2013 \mathrm{Feb}, 20(2): 179-84$.
50. Stepanski EJ, Wyatt JK: Use of sleep hygiene in the treatment of insomnia. Sleep Med Rev 2003 Jun, 7(3):215-25.

5I. Dorsey CM, Lee KA, Scharf MB: Effect of zolpidem on sleep in women with perimenopausal and postmenopausal insomnia: a 4-week, randomized, multicenter, double-blind, placebocontrolled study. Clin Ther 2004 Oct, 26(I0):1578-86.

\section{FIOOOPrime}

52. Joffe H, Petrillo L, Viguera A, Koukopoulos A, Silver-Heilman K, Farrell A, Yu G, Silver M, Cohen LS: Eszopiclone improves insomnia and depressive and anxious symptoms in perimenopausal and postmenopausal women with hot flashes: a randomized, double-blinded, placebo-controlled crossover trial. Am J Obstet Gynecol 2010, 202(2): I7I

\section{FIOOOPrime}

\section{RECOMMENDED}

53. Voshaar RC, van Balkom Al, Zitman FG: Zolpidem is not superior to temazepam with respect to rebound insomnia: a controlled study. Eur Neuropsychopharmacol 2004, 14(4):30I-6.

54. Dobkin RD, Menza M, Bienfait KL, Allen LA, Marin H, Gara MA: Ramelteon for the treatment of insomnia in menopausal women. Menopause international 2009, I5(I):13-8.

\section{FlOOOPRime
RECOMMENDED}

55. Murtagh DR, Greenwood KM: Identifying effective psychological treatments for insomnia: a meta-analysis. J Consult Clin Psychol 1995, 63(1):79-89.

\section{FIOOOPrime}

56. Smith MT, Perlis ML, Park A, Smith MS, Pennington J, Giles DE, Buysse DJ: Comparative meta-analysis of pharmacotherapy and behavior therapy for persistent insomnia. Am J Psychiatry 2002, I59(I):5-11

\section{FlOOOPrime}

RECOMMENDED

57. Wilson SJ, Nutt DJ, Alford C, Argyropoulos SV, Baldwin DS, Bateson AN, Britton TC, Crowe C, Dijk DJ, Espie CA, Gringras P, Hajak G, Idzikowski C, Krystal AD, Nash JR, Selsick H, Sharpley AL, Wade AG: British Association for Psychopharmacology consensus statement on evidence-based treatment of insomnia, parasomnias and circadian rhythm disorders. J Psychopharmacol 20I0, 24(II):1577-60I.

\section{FlOOOPrime
RECOMMENDED}

58. Morin CM, Colecchi C, Stone J, Sood R, Brink D: Behavioral and pharmacological therapies for late-life insomnia: a randomized controlled trial. JAMA I999, 28I(II):99I-9.

59. Edinger JD, Wohlgemuth WK, Radtke RA, Marsh GR, Quillian RE: Cognitive behavioral therapy for treatment of chronic primary insomnia: a randomized controlled trial. JAMA 200I, 285(I4):1856-64.

60. Irwin MR, Cole JC, Nicassio PM: Comparative meta-analysis of behavioral interventions for insomnia and their efficacy in middle-aged adults and in older adults $55+$ years of age. Health Psychol 2006, 25(I):3-I4.

\section{FlOOOPrime
RECOMMENDED}

6I. Nowakowski S, Dowdle CL, Suh S, Siebern A, Manber R: Examination of cognitive behavioral therapy for insomnia in perimenopausal women. Sleep 2012, 35(Suppl):A243.

62. Matthews KA, Everson-Rose SA, Kravitz HM, Lee L, Janssen I, SuttonTyrrell K: Do reports of sleep disturbance relate to coronary and aortic calcification in healthy middle-aged women?: Study of women's health across the nation. Sleep Med 2013 Mar, 14(3):282-7.

63. Sands-Lincoln M, Loucks EB, Lu B, Carskadon MA, Sharkey K, Stefanick ML, Ockene J, Shah N, Hairston KG, Robinson JG, 
Limacher M, Hale L, Eaton CB: Sleep duration, insomnia, and coronary heart disease among postmenopausal women in the Women's Health Initiative. J Womens Health (Larchmt) 2013 Jun, 22(6):477-86.

64. Sofi F, Cesari F, Casini A, Macchi C, Abbate R, Gensini GF: Insomnia and risk of cardiovascular disease: a meta-analysis. Eur J Prev Cardiol 2014 Jan, 2 I(I):57-64.

65. Karlin BE, Trockel M, Taylor CB, Gimeno J, Manber R: National Dissemination of Cognitive Behavioral Therapy for Insomnia in Veterans: Therapist- and Patient-Level Outcomes. J Consult Clin Psychol 2013 Apr, I5.

\section{FlOOOPrime} RECOMMENDED

66. Manber R, Carney C, Edinger J, Epstein D, Friedman L, Haynes PL, Karlin BE, Pigeon W, Siebern AT, Trockel M: Dissemination of CBTI to the non-sleep specialist: protocol development and training issues. Journal of Clinical Sleep Medicine $2012 \mathrm{Apr}$ I5, 8(2):209-18.

67. Carney CE, Manber R. Quiet your mind and get to sleep: Solutions to insomnia for those with depression, anxiety or chronic pain. New Harbinger Publications, 2009.

68. American Academy of Sleep Medicine Task Force: Sleep-related breathing disorders in adults: recommendations for syndrome definition and measurement techniques in clinical research. Sleep 1999 Aug I, 22(5):667-89.

69. Peppard PE, Young T, Barnet JH, Palta M, Hagen EW, Hla KM: Increased prevalence of sleep-disordered breathing in adults. Am J Epidemiol 2013 May, I I77(9): I006-I4.

70. Redline S, Sotres-Alvarez D, Loredo J, Hall M, Patel SR, Ramos A, Shah N, Ries A, Arens R, Barnhart J, Youngblood M, Zee P, Daviglus ML: Sleep-disordered breathing in Hispanic/Latino individuals of diverse backgrounds. The Hispanic Community Health Study/Study of Latinos. Am J Respir Crit Care Med 2014 Feb I, 189(3):335-44.

7I. Franklin KA, Sahlin C, Stenlund H, Lindberg E: Sleep apnoea is a common occurrence in females. Eur Respir J 2013 Mar, $4|(3): 6| 0-5$.

72. Hall MH, Matthews KA, Kravitz HM, Gold EB, Buysse DJ, Bromberger JT, Owens JF, Sowers M: Race and financial strain are independent correlates of sleep in midlife women: the SWAN sleep study. Sleep 2009 Jan, 32(I):73-82.

73. Eliasson AH, Kashani MD, Howard RS, Vernalis MN, Modlin RE: Fatigued on Venus, sleepy on Mars-gender and racial differences in symptoms of sleep apnea. Sleep Breath 2014 Mar, 15.

74. Dursunoglu N, Ozkurt S, Sarikaya S: Is the clinical presentation different between men and women admitting to the sleep laboratory? Sleep Breath 2009 Aug, I3(3):295-8.

75. Bruyneel M, Ninane V: Unattended home-based polysomnography for sleep disordered breathing: current concepts and perspectives. Sleep Med Rev 20I4 Aug, I8(4):34I-7.

76. Kapur V, Strohl KP, Redline S, Iber C, O'Connor G, Nieto J: Underdiagnosis of sleep apnea syndrome in U.S. communities. Sleep Breath 2002 Jun, 6(2):49-54.

77. Young T, Evans L, Finn L, Palta M: Estimation of the clinically diagnosed proportion of sleep apnea syndrome in middleaged men and women. Sleep $1997 \mathrm{Sep}, 20(9): 705-6$.

78. Quintana-Gallego E, Carmona-Bernal C, Capote F, SanchezArmengol A, Botebol-Benhamou G, Polo-Padillo J, Castillo-Gomez J: Gender differences in obstructive sleep apnea syndrome: a clinical study of II66 patients. Respir Med 2004 Oct, 98 (I0):984-9.

79. Bixler EO, Vgontzas AN, Lin HM, Ten Have T, Rein J, Vela-Bueno A, Kales A: Prevalence of sleep-disordered breathing in women: effects of gender. Am J Respir Crit Care Med 200I Mar, 163 (3 Pt I):608-13.

80. Young T, Finn L, Austin D, Peterson A: Menopausal status and sleep-disordered breathing in the Wisconsin Sleep Cohort Study. Am J Respir Crit Care Med 2003 May I, 167(9): I I8I-5.
8I. Dancey DR, Hanly PJ, Soong C, Lee B, Hoffstein V: Impact of menopause on the prevalence and severity of sleep apnea. Chest 200I Jul, I20(I):I5I-5.

82. Hachul H, Frange C, Bezerra AG, Hirotsu C, Pires GN, Andersen ML, Bittencourt L, Tufik S: The effect of menopause on objective sleep parameters: data from an epidemiologic study in Sao Paulo, Brazil. Maturitas 2015 Feb, 80(2): I70-8.

83. Popovic RM, White DP: Upper airway muscle activity in normal women: influence of hormonal status. J Appl Physiol 1998 Mar, 84(3): 1055-62.

84. Driver HS, McLean H, Kumar DV, Farr N, Day AG, Fitzpatrick MF: The influence of the menstrual cycle on upper airway resistance and breathing during sleep. Sleep $2005 \mathrm{Apr}$ I, 28(4):449-56.

85. Saaresranta T, Aittokallio T, Polo-Kantola P, Helenius $H$, Polo $O$ : Effect of medroxyprogesterone on inspiratory flow shapes during sleep in postmenopausal women. Respir Physiol Neurobiol 2003 May 3, 134(2): I3|-43.

86. Shahar E, Redline S, Young T, Boland LL, Baldwin CM, Nieto FJ, O'Connor GT, Rapoport DM, Robbins JA: Hormone replacement therapy and sleep-disordered breathing. Am J Respir Crit Care Med 2003 May, I I67(9): I I86-92.

87. Pickett CK, Regensteiner JG, Woodard WD, Hagerman DD, Weil JV, Moore LG: Progestin and estrogen reduce sleep-disordered breathing in postmenopausal women. J Appl Physiol (1985) 1989 Apr, 66(4):|656-6I.

88. Wesstrom J, Ulfberg J, Nilsson S: Sleep apnea and hormone replacement therapy: a pilot study and a literature review. Acta Obstet Gynecol Scand 2005 Jan, 84(I):54-7.

89. Manber R, Kuo TF, Cataldo N, Colrain IM: The effects of hormone replacement therapy on sleep-disordered breathing in postmenopausal women: a pilot study. Sleep 2003 Mar 15, 26(2): 163-8.

90. Cistulli PA, Barnes DJ, Grunstein RR, Sullivan CE: Effect of shortterm hormone replacement in the treatment of obstructive sleep apnoea in postmenopausal women. Thorax $1994 \mathrm{Jul}$, 49(7):699-702.

9I. Hachul H, Bittencourt LR, Andersen ML, Haidar MA, Baracat EC, Tufik S: Effects of hormone therapy with estrogen and/or progesterone on sleep pattern in postmenopausal women. Int J Gynaecol Obstet 2008 Dec, 103(3):207-I2.

92. Anttalainen U, Saaresranta T, Vahlberg T, Polo O: Short-term medroxyprogesterone acetate in postmenopausal women with sleep-disordered breathing: a placebo-controlled, randomized, double-blind, parallel-group study. Menopause 2014 Apr, 2 I (4):36I-8.

93. Young T, Peppard PE, Taheri S: Excess weight and sleepdisordered breathing. J Appl Physiol 2005 Oct, 99(4):1592-9.

94. Sowers M, Zheng H, Tomey K, Karvonen-Gutierrez C, Jannausch M, $\mathrm{Li}$, Yosef M, Symons J: Changes in body composition in women over six years at midlife: ovarian and chronological aging. J Clin Endocrinol Metab 2007 Mar, 92(3):895-90I.

95. Young T, Hutton R, Finn L, Badr S, Palta M: The gender bias in sleep apnea diagnosis. Are women missed because they have different symptoms? Arch Intern Med I 996 Nov 25, I 56(2I):2445-5 I.

96. Redline S, Schluchter MD, Larkin EK, Tishler PV: Predictors of longitudinal change in sleep-disordered breathing in a nonclinic population. Sleep 2003 Sep, 26(6):703-9.

97. Newman AB, Foster G, Givelber R, Nieto FJ, Redline S, Young T: Progression and regression of sleep-disordered breathing with changes in weight: the Sleep Heart Health Study. Arch Intern Med 2005 Nov 14, 165(20):2408-13.

98. Simpson L, Mukherjee S, Cooper MN, Ward KL, Lee JD, Fedson AC, Potter J, Hillman DR, Eastwood P, Palmer LJ, Kirkness J: Sex differences in the association of regional fat distribution with the severity of obstructive sleep apnea. Sleep $2010 \mathrm{Apr}$, 33(4):467-74.

99. Young T, Shahar E, Nieto FJ, Redline S, Newman AB, Gottlieb DJ, Walsleben JA, Finn L, Enright P, Samet JM: Predictors of sleepdisordered breathing in community-dwelling adults: the 
Sleep Heart Health Study. Arch Intern Med 2002 Apr 22, I62(8):893-900.

100. Edwards BA, Wellman A, Sands SA, Owens RL, Eckert DJ, White DP, Malhotra A: Obstructive sleep apnea in older adults is a distinctly different physiological phenotype. Sleep 20I4, 37(7): 1227-36.

10I. Kirkness JP, Schwartz AR, Schneider H, Punjabi NM, Maly IJ, Laffan AM, McGinley BM, Magnuson T, Schweitzer M, Smith PL, Patil SP: Contribution of male sex, age, and obesity to mechanical instability of the upper airway during sleep. J Appl Physiol (1985 ) 2008 Jun, 104(6):16|8-24.

102. Series F, Roy N, Marc I: Effects of sleep deprivation and sleep fragmentation on upper airway collapsibility in normal subjects. Am J Respir Crit Care Med I 994 Aug, I 50(2):48I-5.

103. Ratnavadivel R, Chau N, Stadler D, Yeo A, Mcevoy RD, Catcheside PG: Marked reduction in obstructive sleep apnea severity in slow wave sleep. J Clin Sleep Med 2009 Dec I5, 5(6):519-24.

104. Ferini-Strambi L, Baietto C, Di Gioia MR, Castaldi P, Castronovo C, Zucconi M, Cappa SF: Cognitive dysfunction in patients with obstructive sleep apnea (OSA): partial reversibility after continuous positive airway pressure (CPAP). Brain Res Bull 2003 Jun 30, $6 I(I): 87-92$

105. Peppard PE, Szklo-Coxe M, Hla KM, Young T: Longitudinal association of sleep-related breathing disorder and depression. Arch Intern Med 2006 Sep 18, 166(16): 1709-15.

\section{F1OOOPrime \\ RECOMMENDE}

106. Reichmuth KJ, Austin D, Skatrud JB, Young T: Association of sleep apnea and type II diabetes: a population-based study. $\mathrm{Am}$ J Respir Crit Care Med 2005 Dec 15, I72(12): I590-5.

\section{FlOOOPrime} RECOMMENDED

107. Marin JM, Carrizo SJ, Vicente E, Agusti AG: Long-term cardiovascular outcomes in men with obstructive sleep apnoeahypopnoea with or without treatment with continuous positive airway pressure: an observational study. Lancet 2005 Mar 19, 365(9464): 1046-53.

\section{FlOOOPRime
RECOMMENDED}

108. Young T, Finn L, Peppard PE, Szklo-Coxe M, Austin D, Nieto FJ, Stubbs R, Hla KM: Sleep disordered breathing and mortality: eighteen-year follow-up of the Wisconsin sleep cohort. Sleep 2008 Aug, 3 I(8): I07|-8.

\section{FlOOOPrime} RECOMMENDED

109. Peppard PE, Young T, Palta M, Skatrud J: Prospective study of the association between sleep-disordered breathing and hypertension. N Engl J Med 2000 May II, 342(19): I378-84.

II0. Hedner J, Bengtsson-Bostrom K, Peker Y, Grote L, Rastam L, Lindblad U: Hypertension prevalence in obstructive sleep apnoea and sex: a population-based case-control study. Eur Respir J 2006 Mar, 27(3):564-70.

III. Randby A, Namtvedt SK, Hrubos-Strom H, Einvik G, Somers VK, Omland T: Sex-dependent impact of OSA on digital vascular function. Chest $2013 \mathrm{Sep}$, 144(3):915-22.

I 12. Faulx MD, Larkin EK, Hoit BD, Aylor JE, Wright AT, Redline S: Sex influences endothelial function in sleep-disordered breathing. Sleep 2004 Sep 15, 27(6): I I 13-20.

I 13. Ljunggren M, Lindahl B, Theorell-Haglow J, Lindberg E: Association between obstructive sleep apnea and elevated levels of type B natriuretic peptide in a community-based sample of women. Sleep 2012 Nov, 35(II):152I-7.

II4. Theorell-Haglow J, Berne C, Janson C, Lindberg $E$ : The role of obstructive sleep apnea in metabolic syndrome: a population-based study in women. Sleep Med 20II Apr, I2(4):329-34.
II5. Campos-Rodriguez F, Martinez-Garcia MA, Reyes-Nunez N, Caballero-Martinez I, Catalan-Serra P, Almeida-Gonzalez CV: Role of sleep apnea and continuous positive airway pressure therapy in the incidence of stroke or coronary heart disease in women. Am J Respir Crit Care Med 2014 Jun I5, 189(I2):1544-50.

I16. Campos-Rodriguez F, Martinez-Garcia MA, de la Cruz-Moron I, Almeida-Gonzalez C, Catalan-Serra P, Montserrat JM: Cardiovascular mortality in women with obstructive sleep apnea with or without continuous positive airway pressure treatment: a cohort study. Ann Intern Med 2012 Jan 17, I 56(2): I I5-22.

117. Hall MH, Okun ML, Sowers M, Matthews KA, Kravitz HM, Hardin K, Buysse DJ, Bromberger JT, Owens JF, Karpov I, Sanders MH: Sleep is associated with the metabolic syndrome in a multi-ethnic cohort of midlife women: the SWAN Sleep Study. Sleep 2012 Jun, 35(6):783-90.

I 18. Matthews KA, Zheng H, Kravitz HM, Sowers M, Bromberger JT, Buysse DJ, Owens JF, Sanders M, Hall M: Are inflammatory and coagulation biomarkers related to sleep characteristics in mid-life women?: Study of Women's Health across the Nation sleep study. Sleep 2010 Dec 13, 33(12):1649-55.

119. Weaver TE, Grunstein RR: Adherence to continuous positive airway pressure therapy: the challenge to effective treatment. Proc Am Thorac Soc 2008 Feb 15, 5(2): 173-8.

120. Sin DD, Mayers I, Man GC, Pawluk L: Long-term compliance rates to continuous positive airway pressure in obstructive sleep apnea: a population-based study. Chest 2002 Feb, I 2 I (2):430-5.

121. McArdle N, Devereux G, Heidarnejad H, Engleman HM, Mackay TW, Douglas NJ: Long-term use of CPAP therapy for sleep apneal hypopnea syndrome. Am 」 Respir Crit Care Med 1999 Apr, I59(4 Pt I): I 108-14.

122. Pelletier-Fleury N, Rakotonanahary D, Fleury B: The age and other factors in the evaluation of compliance with nasal continuous positive airway pressure for obstructive sleep apnea syndrome. A Cox's proportional hazard analysis. Sleep Med 200I May, 2(3):225-32.

123. Woehrle H, Graml A, Weinreich G: Age- and gender-dependent adherence with continuous positive airway pressure therapy. Sleep Med 20II Dec, I2(10): 1034-6.

124. Nino-Murcia G, McCann CC, Bliwise DL, Guilleminault C, Dement WC: Compliance and side effects in sleep apnea patients treated with nasal continuous positive airway pressure. West J Med 1989 Feb, I50(2):165-9.

125. Ye L, Pien GW, Ratcliffe S,, Weaver TE: Gender differences in obstructive sleep apnea and treatment response to continuous positive airway pressure. J Clin Sleep Med 2009 Dec 15, 5(6):5 12-8.

126. Hoffstein V: Review of oral appliances for treatment of sleepdisordered breathing. Sleep Breath 2007 Mar, I I (I): I-22

127. Marklund M, Stenlund $\mathrm{H}$, Franklin KA: Mandibular advancement devices in $\mathbf{6 3 0}$ men and women with obstructive sleep apnea and snoring: tolerability and predictors of treatment success. Chest 2004 Apr, I 25(4): I270-8.

\section{FECOMMENDED}

128. Epstein LJ, Kristo D, Strollo PJ, Jr., Friedman N, Malhotra A, Patil SP, Ramar K, Rogers R, Schwab RJ, Weaver EM, Weinstein MD: Clinical guideline for the evaluation, management and long-term care of obstructive sleep apnea in adults. J Clin Sleep Med 2009 Jun I5, 5(3):263-76.

129. Foster GD, Borradaile KE, Sanders MH, Millman R, Zammit G, Newman AB, Wadden TA, Kelley D, Wing RR, Pi-Sunyer FX, Reboussin D, Kuna ST, Sleep AHEAD Research Group of Look AHEAD Research Group: A randomized study on the effect of weight loss on obstructive sleep apnea among obese patients with type 2 diabetes: the Sleep AHEAD study. Arch Intern Med 2009 Sep 28, 169(17):1619-26. 
130. Kuna ST, Reboussin DM, Borradaile KE, Sanders MH, Millman RP, Zammit G, Newman AB, Wadden TA, Jakicic JM, Wing RR, Pi-Sunyer FX, Foster GD, Sleep AHEAD Research Group of the Look AHEAD Research Group: Long-term effect of weight loss on obstructive sleep apnea severity in obese patients with type 2 diabetes. Sleep 2013 May, 36(5):64I-649A.

\section{FlOOOPrime}

\section{RECOMMENDED}

13I. Veasey SC, Guilleminault C, Strohl KP, Sanders MH, Ballard RD, Magalang UJ: Medical therapy for obstructive sleep apnea: a review by the Medical Therapy for Obstructive Sleep Apnea Task Force of the Standards of Practice Committee of the American Academy of Sleep Medicine. Sleep 2006 Aug, 29(8): 1036-44.

132. Kushida CA, Littner MR, Hirshkowitz M, Morgenthaler TI, Alessi CA, Bailey D, Boehlecke B, Brown TM, Coleman J, Jr., Friedman L, Kapen S, Kapur VK, Kramer M, Lee-Chiong T, Owens J, Pancer JP, Swick TJ, Wise MS: Practice parameters for the use of continuous and bilevel positive airway pressure devices to treat adult patients with sleep-related breathing disorders. Sleep 2006 Mar, 29(3):375-80.
133. Aurora RN, Casey KR, Kristo D, Auerbach S, Bista SR, Chowdhuri S, Karippot A, Lamm C, Ramar K, Zak R, Morgenthaler TI: Practice parameters for the surgical modifications of the upper airway for obstructive sleep apnea in adults. Sleep 2010 Oct, 33(I0): I 1408-13.

134. Morgenthaler TI, Kapen S, Lee-Chiong T, Alessi C, Boehlecke B, Brown T, Coleman J, Friedman L, Kapur V, Owens J, Pancer J, Swick T: Practice parameters for the medical therapy of obstructive sleep apnea. Sleep 2006 Aug, 29(8): 103 I-5.

135. Campos-Rodriguez F, Martinez-Garcia MA, Montserrat JM: Gender differences in treatment recommendations for sleep apnea. Clin Pract 2012, 9(5):565-78.

136. Somers VK, White DP, Amin R, Abraham WT, Costa F, Culebras A, Daniels S, Floras JS, Hunt CE, Olson LJ, Pickering TG, Russell R, Woo M, Young T: Sleep apnea and cardiovascular disease: an American Heart Association/American College of Cardiology Foundation Scientific Statement from the American Heart Association Council for High Blood Pressure Research Professional Education Committee, Council on Clinical Cardiology, Stroke Council, and Council on Cardiovascular Nursing. J Am Coll Cardiol 2008 Aug 19, 52(8):686-7I7. 